\title{
EFICIÊNCIA DA ESCARIFICAÇÃO MECÂNICA E BIOLÓGICA NA MELHORIA DOS ATRIBUTOS FÍSICOS DE UM LATOSSOLO MUITO ARGILOSO E NO INCREMENTO DO RENDIMENTO DE SOJA ${ }^{(1)}$
}

\author{
Rodrigo da Silveira Nicoloso ${ }^{(2)}$, Telmo Jorge Carneiro Amado ${ }^{(3)}$, \\ Sérgio Schneider ${ }^{(4)}$, Mastrângello Enívar Lanzanova ${ }^{(5)}$, Vitor \\ Cauduro Girardello ${ }^{(6)} \&$ Jardes Bragagnolo ${ }^{(6)}$
}

\begin{abstract}
RESUMO
A compactação é uma das principais causas de decréscimo da produtividade dos solos agrícolas. A escarificação mecânica tem sido sugerida para reduzir a compactação do solo em áreas sob sistema de semeadura direta consolidada. Outra opção para aliviar a compactação é o uso de plantas de cobertura com sistema radicular pivotante e bem desenvolvido, como o nabo-forrageiro, com capacidade de crescer em camadas compactadas, formar bioporos estáveis e melhorar os atributos físicos do solo. O objetivo deste trabalho foi avaliar a eficiência do método mecânico (escarificador) e do método biológico (nabo-forrageiro) de descompactação do solo, ou de ambos associados, em promover a melhoria dos atributos físicos de um Latossolo de textura muito argilosa e o rendimento de grãos da cultura da soja manejada sob semeadura direta. Os tratamentos utilizados foram: aveia-preta em semeadura direta (SD-Av), consórcio de nabo-forrageiro e aveia-preta em semeadura direta (SD-Nb+Av), aveia-preta em solo escarificado (ESC-Av) e consórcio de nabo-forrageiro e aveia-preta em solo escarificado (ESC$\mathrm{Nb}+\mathrm{Av}$ ). Foram avaliadas a densidade, macroporosidade, microporosidade e porosidade total do solo nas camadas $0-0,05 ; 0,05-0,10 ; 0,10-0,15$; e $0,15-0,20 \mathrm{~m}$, resistência do solo à penetração, umidade gravimétrica e infiltração de água no solo, no momento do pleno florescimento da soja. Além disso, foram determinadas a produção de matéria seca das plantas de cobertura de solo de inverno e o
\end{abstract}

\footnotetext{
(1) Recebido para publicação em setembro de 2007 e aprovado em junho de 2008.

(2) Doutorando em Engenharia Agrícola, Universidade Federal de Santa Maria - UFSM. Av. Roraima 1000, CEP 97105-900 Santa Maria (RS). Bolsista CAPES. E-mail: rsnicoloso@mail.ufsm.br

(3) Professor Associado do Departamento de Solos, UFSM. Bolsista CNPq. E-mail: tamado@smail.ufsm.br

(4) Engenheiro-Agrônomo, Gerente técnico da Cooperativa Mista São Luiz - COOPERMIL. Santa Rosa (RS). E-mail: sergio_schneider@terra.com.br

(5) Professor Assistente da Universidade Estadual do Rio Grande do Sul - UERGS. Rua Cipriano Barata 47, CEP $98600-000$ Três Passos (RS). E-mail: mastrangello-lanzanova@uergs.edu.br

(6) Mestrando em Ciência do Solo. UFSM. Bolsista CNPq. E-mails: vitor@mail.ufsm.br; jardes@yahoo.com.br
} 
rendimento de soja no verão. Os tratamentos não afetaram significativamente a densidade do solo em nenhuma das camadas avaliadas, no entanto os tratamentos $\mathrm{SD}-\mathrm{Nb}+\mathrm{Av}$ e ESC-Nb+Av duplicaram os valores de macroporosidade do solo na média da camada $0-0,20 \mathrm{~m}$, com efeitos mais pronunciados nas camadas mais superficiais do solo. Os tratamentos SD-Nb+Av e ESC-Nb+Av reduziram a resistência do solo à penetração em relação ao tratamento SD-Av, enquanto o tratamento ESC-Av teve comportamento intermediário. Os tratamentos SD-Nb+Av e ESC-Nb+Av aumentaram, em média, 46,6 \% a lâmina de água infiltrada em relação aos tratamentos SD-Av e ESC-Av. O maior rendimento de grãos de soja foi observado no tratamento ESC-Nb+Av (3,73 $\left.\mathrm{Mg} \mathrm{ha}^{-1}\right)$, que não diferiu significativamente do SD-Nb+Av (3,49 $\left.\mathrm{Mg} \mathrm{ha}^{-1}\right)$. A escarificação mecânica do solo teve efeito temporário, e não foram constatadas melhores condições físicas do solo após nove meses, com exceção do aumento da porosidade total e macroporosidade do solo na camada 0-0,05 m. Por outro lado, a escarificação biológica aumentou a macroporosidade do solo, diminuiu sua resistência à penetração e melhorou a infiltração de água. A escarificação mecânica foi uma alternativa eficiente em melhorar as condições físicas do Latossolo textura muito argilosa quando associada à escarificação biológica, que preveniu a reconsolidação do solo.

Termos de indexação: compactação do solo, escarificador, plantas de cobertura, infiltração de água, resistência do solo à penetração.

\title{
SUMMARY: EFFICIENCY OF MECHANICAL AND BIOLOGICAL CHISELING IN THE IMPROVEMENT OF PHYSICAL ATTRIBUTES OF A HEAVY CLAY OXISOL AND THE INCREMENT OF SOYBEAN YIELD
}

\begin{abstract}
Compaction is one of the main causes of yield decreases in agricultural soils. Mechanical chiseling has been suggested to reduce soil compaction in long-term no-tillage systems. Another option to alleviate soil compaction is the use of cover crops, such as forage radish, with a well-developed tap root system and the capacity of growing into soil compacted layers, forming stable biopores and improving the soil physical properties. This study aimed to evaluate the efficiency of a mechanical (chisel plow) and biological (forage radish) soil decompaction method or the combination of both to improve the physical properties of a very clayey texture Oxisol and to increase soybean grain yield under no-tillage. The treatments were: black oat on no-till (NT-O), consortium of forage radish and black oat on no-till $(\mathrm{NT}-\mathrm{R}+\mathrm{O})$, black oat on chiseled soil $(\mathrm{CH}-\mathrm{O})$ and consortium of forage radish and black oat on chiseled soil $(\mathrm{CH}-\mathrm{R}+\mathrm{O})$. The following properties were evaluated: soil bulk density, macroporosity, microporosity and total porosity in the layers $0-0.05,0.05-0.10$, $0.10-0.15$ and $0.15-0.20 \mathrm{~m}$, soil penetration resistance, soil moisture and soil water infiltration at soybean flowering. The winter cover biomass production and soybean yield were also measured. The treatments did not affect the soil bulk density significantly at any of the soil depths. However, the treatments $\mathrm{NT}-\mathrm{R}+\mathrm{O}$ and $\mathrm{CH}-\mathrm{R}+\mathrm{O}$ doubled the mean soil macroporosity values in the $0-0.20 \mathrm{~m}$ layer, with more pronounced effects in the upper soil layers. The treatments $N T-R+O$ and $C H-R+O$ reduced soil penetration resistance compared to $\mathrm{NT}+\mathrm{O}$, while treatment $\mathrm{CH}$-O had intermediate results. The treatments $\mathrm{NT}$ $R+O$ and $C H-R+O$ increased the accumulated infiltrated water by 44.6 as compared to treatments NT-O and $\mathrm{CH}-\mathrm{O}$. The highest soybean yields were observed in the treatment $C H-R+O\left(3.73 \mathrm{Mg} \mathrm{ha}^{-1}\right)$, which did not differ significantly from treatment $N T-R+O$ (3.49 Mg ha ${ }^{-1}$ ). The effect of winter mechanical chiseling was temporary and nine months later no soil physical improvements were observed, apart from the increase of total porosity and macroporosity in the 0-0.05 m layer. Biological chiseling increased soil macroporosity, reduced soil penetration resistance and improved soil water infiltration. Mechanical chiseling was only efficient to improve the soil physical conditions when associated with biological chiseling, which prevented soil reconsolidation.
\end{abstract}

Index terms: soil compaction, chisel, cover crops, water infiltration, soil penetration resistance. 


\section{INTRODUÇÃO}

A compactação é um dos principais processos de degradação dos solos agrícolas (Horn et al., 2003) e se expressa pelo aumento da densidade do solo e pela redução do seu espaço poroso em resposta a um histórico de cargas ou pressões exercidas na sua superfície (Baver et al., 1972), especialmente em elevada umidade (Silva et al., 2002). A compactação reduz a taxa de infiltração de água no solo (Lanzanova et al., 2007) e aumenta o escoamento superficial (Canillas \& Salokhe, 2001), o que limita a disponibilidade de água para as plantas. Em solo compactado, o sistema radicular concentra-se próximo da superfície (Muller et al., 2001), tornando as plantas mais susceptíveis a déficits hídricos e com menor eficiência em absorver os nutrientes (Rosolem et al. 1994). Na região do planalto, no Rio Grande do Sul, onde predominam Latossolos de textura muito argilosa, Michelon (2005) observou, em estudo exploratório das condições físicas em sistema de semeadura direta (SD) sob pivô central, que 66,5 \% das áreas avaliadas apresentavam compactação.

Alguns trabalhos reportaram maior nível de compactação em solos sob SD, por longo período de tempo, do que solos manejados com preparo convencional (PC) (Vasquez et al., 1989; Pierce et al., 1994). No entanto, outros observaram que, sob SD, os solos apresentaram maior taxa de infiltração e retenção de água e menor escoamento superficial que solos sob PC (Sidiras et al., 1982; Chang \& Lindwall, 1992; Benjamin, 1993), especialmente por apresentarem maior estabilidade de agregados e pela formação de bioporos verticais (Lal \& Vandoren, 1990).

A escarificação mecânica tem sido sugerida para aliviar a compactação do solo em áreas de SD consolidado (Camara \& Klein, 2005b), pois reduziu a densidade do solo e melhorou a condutividade hidráulica e a taxa de infiltração de água. No entanto, o seu efeito é temporário e o solo escarificado tende a se reconsolidar, retornando em pouco tempo à sua condição original (Busscher et al., 2002), exigindo a repetição da operação regularmente. Secco \& Reinert (1997) observaram que o efeito residual da escarificação em um Latossolo de textura muito argilosa do Rio Grande do Sul (RS) não foi superior a 10 meses.

Além do método mecânico, a alternativa é o uso de plantas de cobertura com sistema radicular pivotante e bem desenvolvido (método biológico), como o naboforrageiro, com capacidade de crescer em camadas compactadas, formar bioporos estáveis e melhorar os atributos físicos do solo (Cubilla et al., 2002). No entanto, Kubota et al. (2005), em avaliação realizada após o manejo do nabo-forrageiro, não observaram efeito imediato da cultura de cobertura em melhorar as condições físicas de um Argissolo de textura média e, ao contrário, verificaram aumento da densidade do solo na camada de $0-0,05 \mathrm{~m}$. Este efeito foi atribuído à pressão exercida no solo pelas raízes do nabo- forrageiro, devido ao grande diâmetro de sua raiz pivotante principal. No entanto, em avaliação realizada após a colheita da cultura da soja, esses autores observaram aumento da macroporosidade, de porosidade total e da estabilidade de agregados do solo em áreas que anteriormente receberam naboforrageiro no inverno em relação àquelas onde foi cultivado trigo.

Para cobertura do solo, a densidade de semeadura do nabo-forrageiro recomendada é de 15 a $20 \mathrm{~kg} \mathrm{ha}^{-1}$ de sementes (Calegari, 1990). No entanto, alguns agricultores têm aumentado essa densidade, visando diminuir o diâmetro e aumentar o número de raízes pivotantes por unidade de área. Teoricamente, a pressão lateral da raiz do nabo-forrageiro sobre o solo seria reduzida e o número de bioporos formados pelas raízes após a sua decomposição aumentado. A eficiência dessa estratégia de manejo sobre a melhoria dos atributos físicos do solo ainda não está comprovada por trabalhos científicos.

A eficiência do método biológico também depende do estado inicial de compactação do solo. Mesmo espécies indicadas para esta finalidade têm o desenvolvimento de suas raízes limitado quando o solo apresenta níveis muito elevados de densidade e resistência à penetração (Cubilla et al., 2002). Avaliando a capacidade do sistema radicular de 22 espécies em se desenvolver em um substrato que apresentava 4,2 MPa de resistência à penetração, Materechera et al. (1991) observaram aumento do diâmetro e redução média de 90 \% no comprimento das raízes em relação ao tratamento com $0 \mathrm{MPa}$ de resistência à penetração. No mesmo trabalho, os autores observaram uma correlação positiva entre o diâmetro da raiz e a sua capacidade de crescimento em solo compactado. Por essa razão, concluiu-se que o nabo-forrageiro apresentou maior potencial em atuar como escarificador biológico do que a aveia. Em estudo desenvolvido em casa de vegetação, utilizando um Latossolo com $527 \mathrm{~g} \mathrm{~kg}^{-1}$ de argila, Cintra \& Mielniczuk (1983) observaram que a raiz pivotante da soja não conseguiu penetrar numa camada de solo com densidade de $1,30 \mathrm{Mg} \mathrm{m}^{-3}$, enquanto a colza somente teve a sua raiz pivotante afetada quando a densidade do solo foi de 1,60 $\mathrm{Mg} \mathrm{m}^{-3}$.

A densidade do solo que restringe o crescimento do sistema radicular de algumas espécies comerciais e a sua relação com a produtividade têm sido tema de vários trabalhos. Suzuki et al. (2006), com base em dados de literatura, definiram uma relação entre teor de argila e densidade do solo restritiva para o desenvolvimento do sistema radicular. Reichert et al. (2003) sugeriram valores críticos de densidade para solos de textura muito argilosa variando entre 1,25 e $1,30 \mathrm{Mg} \mathrm{m}^{-3}$. Beutler et al. (2005) observaram a redução no rendimento de grãos de soja quando um Latossolo com $517 \mathrm{~g} \mathrm{~kg}^{-1}$ de argila apresentou valores de densidade superiores a $1,29 \mathrm{Mg} \mathrm{m}^{-3}$ ou densidade relativa superior a 0,84. No Rio Grande do Sul, na 
região noroeste, onde ocorrem Latossolos de textura muito argilosa, tem se observado as maiores perdas de produção agrícola, quando da ocorrência de déficits hídricos durante o verão.

O objetivo deste trabalho foi avaliar a eficiência do método mecânico (escarificador) e do método biológico (nabo-forrageiro) de descompactação do solo, ou de ambos associados, em promover a melhoria dos atributos físicos de um Latossolo de textura muito argilosa e o incremento do rendimento de grãos da cultura da soja manejada sob semeadura direta.

\section{MATERIAL E MÉTODOS}

Para esta pesquisa, foi instalado um experimento de campo em quatro áreas de agricultores associados da COPERMIL (Cooperativa Mista São Luis Ltda.), no município de Santa Rosa, região noroeste do Rio Grande do Sul. As áreas foram selecionadas por apresentarem histórico de compactação do solo como raízes com crescimento limitado ao sulco de semeadura, raízes deformadas e desviadas, restrições ao desenvolvimento de plantas em períodos de estiagem e histórico de monocultura de soja sob SD. O clima da região é do tipo subtropical úmido, com incidência de estiagens no verão e outono (Maluf, 2000). A precipitação e a temperatura média anual são de $1.769 \mathrm{~mm}$ e $19,5^{\circ} \mathrm{C}$, respectivamente, para o período 1931-1974 (IPAGRO, 1989). O solo é descrito como Latossolo Vermelho distroférrico típico (Embrapa, 2006). O quadro 1 apresenta a localização e as principais características físicas e químicas da camada 0-0,20 m do solo das quatro áreas que compõem este trabalho. A composição granulométrica foi determinada pela dispersão das amostras em $\mathrm{NaOH}$ e agitação por $16 \mathrm{~h}$. O conteúdo de argila foi obtido pelo método da pipeta (Gee \& Bauder, 1986). Os atributos químicos do solo foram determinados pela metodologia descrita por Tedesco et al. (1995).
O experimento foi instalado em maio de 2006. Até então, as áreas eram manejadas sob SD para a produção de soja e trigo. Em março de 2006, foram tomadas amostras para avaliação das condições físicas iniciais do solo de cada área experimental. Foram coletadas quatro amostras indeformadas de solo em cada área nas profundidades de $0-0,05 ; 0,05-0,10$; 0,10-0,15; e 0,15-0,20 m, com o auxílio de anéis de aço com volume conhecido. Foram determinadas a densidade do solo (Ds) pelo método do anel volumétrico; a porosidade total $(\mathrm{Pt})$ pela percentagem de saturação de água do solo; e a microporosidade (Mi) e macroporosidade do solo (Ma) pela 'mesa de tensão' (Embrapa, 1997).

O delineamento experimental utilizado foi de blocos ao acaso, com quatro tratamentos e quatro repetições, e cada área experimental constituía uma repetição. As parcelas tinham dimensões de 25 x 100 m. Os tratamentos utilizados foram: (a) aveia-preta em semeadura direta (SD-Av), com a semeadura em linha de $100 \mathrm{~kg} \mathrm{ha}^{-1}$ de sementes viáveis de aveia-preta (Avena strigosa Schreb), com espaçamento entre linhas de 0,175 m; (b) consórcio de nabo-forrageiro e aveiapreta em semeadura direta (SD-Nb+Av), com a semeadura em linha de $30 \mathrm{~kg} \mathrm{ha}^{-1}$ de sementes viáveis de nabo-forrageiro (Raphanus sativus L. var. oleiferus Metzg.) e $70 \mathrm{~kg} \mathrm{ha}^{-1}$ de aveia-preta, com espaçamento entre linhas de 0,175 m; (c) aveia-preta em solo escarificado (ESC-Av); (d) consórcio de nabo-forrageiro e aveia-preta em solo escarificado (ESC-Nb+Av). Neste trabalho, utilizou-se a estratégia de aumento da população de plantas de nabo-forrageiro em relação àquela recomendada para cobertura do solo. As culturas de cobertura de inverno foram adubadas com a aplicação de $100 \mathrm{~kg} \mathrm{ha}^{-1}$ de adubo NPK com fórmula 02-20-30. A escarificação foi realizada 10 dias antes da semeadura das culturas de cobertura de inverno na profundidade média de $0,30 \mathrm{~m}$, com escarificador de sete hastes espaçadas 0,50 m entre si. No momento da escarificação, o solo estava em condição friável.

Quadro 1. Localização e características do Latossolo Vermelho distroférrico na camada 0-0,20 m nas quatro áreas experimentais

\begin{tabular}{|c|c|c|c|c|c|c|c|c|c|c|c|}
\hline Área & Coordenada & Areia & Silte & Argila & MO & $\mathbf{p H ~} \mathrm{H}_{2} \mathrm{O}$ & $\mathbf{P}$ & $\mathbf{K}$ & $\mathbf{C a}$ & Mg & $\mathbf{V}$ \\
\hline & & \multicolumn{4}{|c|}{$\mathrm{g} \mathrm{kg}^{-1}$} & $1: 1$ & $\mathrm{mg} \mathrm{dm}{ }^{-3}$ & \multicolumn{3}{|c|}{$-\mathrm{mmol}_{\mathrm{c}} \mathrm{dm}^{-3}-$} & $\%$ \\
\hline A. Gassen & $\begin{array}{l}27^{\circ} 50^{\prime} 39.40 " \mathrm{~S} \\
54^{\circ} 28^{\prime} 31.80 " \mathrm{O}\end{array}$ & 39 & 342 & 619 & 32 & 5,5 & 10 & 3,4 & 93 & 56 & 66 \\
\hline E. Jantsch & $\begin{array}{l}27^{\circ} 53 ’ 06.10^{\prime \prime} \mathrm{S} \\
54^{\circ} 26{ }^{\circ} 25.49^{\prime} \mathrm{O}\end{array}$ & 51 & 298 & 651 & 34 & 6,2 & 11 & 3,1 & 88 & 66 & 76 \\
\hline H. Fabrício & $\begin{array}{l}27^{\circ} 47^{\prime} 16.54 " \mathrm{~S} \\
54^{\circ} 30^{\prime} 45.53^{\prime \prime O}\end{array}$ & 65 & 331 & 604 & 33 & 5,4 & 13 & 3,8 & 72 & 57 & 62 \\
\hline M. Racho & $\begin{array}{l}27^{\circ} 55^{\prime} 54.49^{\prime \prime} \mathrm{S} \\
54^{\circ} 35^{\prime} 11.17 ” \mathrm{O}\end{array}$ & 33 & 277 & 690 & 31 & 5,3 & 8 & 4,2 & 66 & 53 & 61 \\
\hline Média & - & 47 & 312 & 641 & 32 & 5,6 & 10 & 3,6 & 80 & 58 & 66 \\
\hline
\end{tabular}


Em outubro de 2006, por ocasião do final do período de florescimento do nabo-forrageiro, foram coletadas amostras da parte aérea das plantas de cobertura. Para isso, foram coletadas quatro subamostras de $0,49 \mathrm{~m}^{2}$ por parcela. O material vegetal coletado foi levado à estufa e seco a $65^{\circ} \mathrm{C}$ até peso constante. Logo depois, as áreas experimentais foram manejadas com a passagem de um rolo-faca para a posterior semeadura direta da cultura da soja.

A soja (Glycine max (L.) Merr.), cultivar Coodetec 214RR, foi semeada em sistema de semeadura direta no mês de novembro de 2006, com a utilização de uma população de 250.000 plantas ha $^{-1}$ e espaçamento de 0,50 m entre linhas de uma semeadora equipada com sistema de sulcador para deposição do adubo a aproximadamente $0,06 \mathrm{~m}$ de profundidade e sistema de sulcador para deposição das sementes a cerca de $0,03 \mathrm{~m}$ de profundidade. As sementes de soja foram inoculadas com Rhizobium específico para a cultura. A adubação utilizada foi de $250 \mathrm{~kg} \mathrm{ha}^{-1}$ de adubo NPK 02 20-30. Os demais tratos culturais seguiram as recomendações técnicas vigentes para o Rio Grande do Sul (Reunião..., 2006).

Durante o período de florescimento da soja, no mês de fevereiro de 2007 , foram realizadas coletas de quatro amostras indeformadas de solo por parcela, nas profundidades de $0-0,05 ; 0,05-0,10 ; 0,10-0,15$; e 0,15-0,20 m, utilizando anéis de aço com volume conhecido, totalizando 16 amostras por tratamento em cada profundidade. Essas amostras foram utilizadas para a determinação da densidade, macroporosidade, microporosidade e porosidade total do solo.

$\mathrm{Na}$ mesma ocasião, também foi determinada a resistência mecânica do solo à penetração $(\mathrm{RP})$, em intervalos de 0,01 m até a profundidade de $0,20 \mathrm{~m}$, com 25 pontos de avaliação por parcela, totalizando 100 pontos por tratamento, utilizando um penetrômetro digital fabricado por DLG Automação Ltda., modelo PNT-2000, com ponta cônica de $30^{\circ}$. Concomitantemente, também foi determinada a umidade gravimétrica do solo nas camadas $0-0,05$; $0,05-0,10 ; 0,10-0,15$; e $0,10-0,20 \mathrm{~m}$ com a tomada de quatro amostras de solo por parcela.

Ainda nesse período, foi realizada a avaliação da infiltração de água no solo pelo método dos duplos anéis concêntricos, descrito em Embrapa (1997) e adaptado por Lanzanova et al. (2007). O ajuste dos dados foi realizado segundo a equação de Kostiakov $\left(\mathrm{LI}=\mathrm{kt}^{\mathrm{a}}\right.$ ), em que LI representa a lâmina de água infiltrada no solo em função do tempo $t$, e os parâmetros $k$ e a são constantes empíricas (Hillel, 1998).

O rendimento de soja foi determinado através da coleta das plantas em $10 \mathrm{~m}$ lineares de soja por amostra, totalizando quatro amostras por parcela $\mathrm{e}$ 16 amostras por tratamento. Os resultados foram expressos com base na umidade de $13 \%$ dos grãos.

Os resultados experimentais foram submetidos à análise de variância e comparação de médias pelo teste de Tukey, a $5 \%$, análise de regressão para a taxa de infiltração de água no solo e relação entre os parâmetros avaliados.

\section{RESULTADOS E DISCUSSÃO}

\section{Condições iniciais de compactação das áreas experimentais}

Utilizando como referência o desvio-padrão da média da Ds das quatro áreas selecionadas para este trabalho, verifica-se que estas apresentavam inicialmente níveis de compactação do solo similares (Figura 1). Além disso, tomando como referência o valor de densidade restritivo ao crescimento de raízes de $1,32 \mathrm{Mg} \mathrm{m}^{-3}$ para solos com $640 \mathrm{~g} \mathrm{~kg}^{-1}$ de argila, proposto por Suzuki et al. (2006), observa-se que as áreas experimentais apresentavam compactação. $\mathrm{O}$ valor médio de Ds das quatro áreas experimentais situou-se ligeiramente acima deste limite crítico na camada de 0,05-0,20 m. Nessa profundidade, o sistema radicular da cultura da soja possivelmente teria limitações ao desenvolvimento (Cintra \& Mielniczuk, 1983), fato que foi observado pelos agricultores em anos anteriores.

Apesar do nível de compactação verificado nas áreas experimentais, as raízes do nabo-forrageiro conseguiram se desenvolver. Cintra \& Mielniczuk (1983) constataram desenvolvimento da colza em condições em que a soja apresentava restrição ao desenvolvimento do seu sistema radicular, devido ao seu grande diâmetro (Materechera et al., 1991). A escarificação

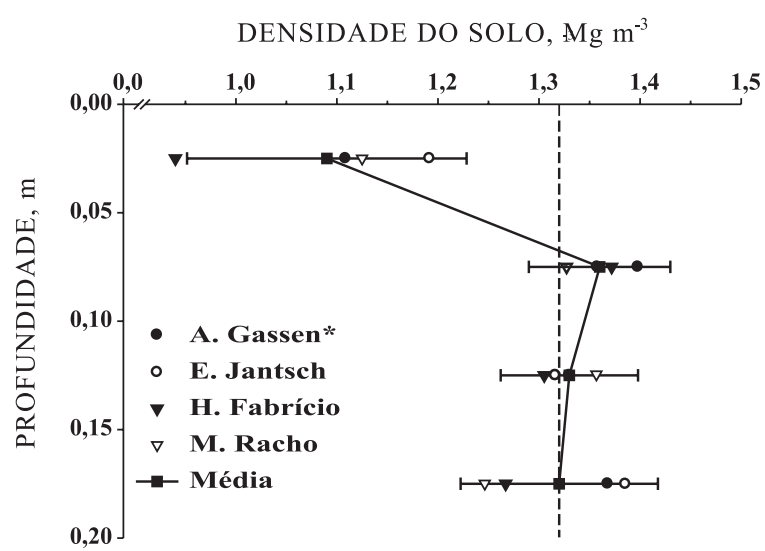

Figura 1. Densidade de um Latossolo Vermelho distroférrico nas quatro áreas experimentais por ocasião da implantação do experimento em Santa Rosa, RS. *A identificação das áreas foi baseada no nome de seus proprietários. As barras horizontais representam o desvio-padrão da média. A linha vertical indica a densidade restritiva ao crescimento de raízes proposto por Suzuki et al. (2006), para solos com $640 \mathrm{~g} \mathrm{~kg}^{-1} \mathrm{de}$ argila. 
biológica pode ser uma alternativa eficiente para melhorar a qualidade física do solo quando os valores de Ds encontram-se ligeiramente acima dos limites críticos (Reichert et al., 2003; Beutler et al., 2005; Suzuki et al., 2006). Possivelmente, quando o solo apresentar níveis de compactação muito superiores aos limites críticos, a escarificação biológica isoladamente poderá não ser eficiente. Abreu et al. (2004) não observaram melhorias nos atributos físicos do solo com o uso da Crotalaria spectabilis como escarificador biológico em um Argissolo textura franco arenosa com elevada resistência à penetração, em relação ao tratamento testemunha com SD de soja.

\section{Produção de MS pelas plantas de cobertura de solo no inverno}

A escarificação não aumentou significativamente a produção de matéria seca (MS) das plantas de cobertura de solo no inverno (Quadro 2). Apesar disso, as produções de MS da aveia-preta e do consórcio de aveia-preta e nabo-forrageiro nos tratamentos que receberam escarificação, antes da semeadura das culturas de inverno, foram 15,4 e $8,1 \%$ superiores às observadas naqueles tratamentos em SD, respectivamente. Esta maior produção de MS pode ser atribuída às melhorias das condições físicas do solo nos meses seguintes à escarificação (Secco \& Reinert, 1997) e à maior decomposição da matéria orgânica do solo (Lovato et al., 2004).

A consorciação do nabo-forrageiro com a aveia-preta promoveu incremento na produção de MS. Nos consórcios SD-Nb+Av e ESC-Nb+Av, os valores de MS foi 89,4 e $77,5 \%$ maiores do que nos tratamentos SDAv e ESC-Av, respectivamente. A maior produção de fitomassa observada nos consórcios de nabo-forrageiro e aveia-preta foi relatada anteriormente por Giacomini et al. (2003) e Silva et al. (2007). Segundo os primeiros autores, o nabo-forrageiro se beneficia da maior

Quadro 2. Produção de matéria seca de plantas de cobertura de solo no inverno em um Latossolo Vermelho distroférrico sob diferentes sistemas de manejo

\begin{tabular}{ll}
\hline Tratamento & Matéria seca \\
\hline & $M g \mathrm{~h} \mathrm{a}^{-1}$ \\
SD $-\mathrm{Av}$ & $4,16 \mathrm{~b}^{*}$ \\
SD $-\mathrm{Nb}+\mathrm{Av}$ & $7,88 \mathrm{a}$ \\
ESC $-\mathrm{Av}$ & $4,80 \mathrm{~b}$ \\
ESC $-\mathrm{Nb}+\mathrm{Av}$ & $8,52 \mathrm{a}$
\end{tabular}

SD-Av: aveia-preta em semeadura direta; SD-Nb+Av: consórcio de nabo-forrageiro e aveia-preta em semeadura direta; ESC-Av: aveia-preta em solo escarificado; ESC-Nb+Av: consórcio de nabo-forrageiro e aveia-preta em solo escarificado. *Médias seguidas pelas mesmas letras não diferem entre si pelo teste de Tukey $(p<0,05)$. disponibilidade de nitrogênio em solos anteriormente cultivados com leguminosas, como a soja, o que reflete em aumento da produção de MS do consórcio e no domínio da produção de fitomassa do nabo-forrageiro em relação à aveia-preta.

\section{Atributos físicos do solo}

Não houve diferença significativa entre os valores de Ds observados em nenhuma das camadas de solo avaliadas. Na camada $0-0,05 \mathrm{~m}$, o tratamento SD$\mathrm{Nb}+\mathrm{Av}$ apresentou um valor de Ds numericamente superior aos demais, inclusive ao solo em sua condição original (Quadro 3). Tal resultado se assemelha ao de Kubota et al. (2005), que observaram Ds significativamente maior na camada $0-0,05 \mathrm{~m}$ do solo após o uso do nabo-forrageiro. Trabalhando com solo de textura média, os autores atribuíram o aumento de Ds na camada mais superficial à pressão lateral exercida pelas raízes do nabo-forrageiro, devido ao grande diâmetro de sua raiz pivotante principal. Kubota et al. (2005) utilizaram $20 \mathrm{~kg} \mathrm{ha}^{-1}$ de sementes de nabo-forrageiro, e neste trabalho foram utilizados $30 \mathrm{~kg} \mathrm{ha}{ }^{-1}$. A maior população de plantas utilizada neste trabalho possivelmente foi eficiente em reduzir o diâmetro médio e aumentar o número de raízes do nabo-forrageiro por área, o que amenizaria a pressão causada pelo crescimento da raiz principal, além de aumentar o número de bioporos formados no solo após a decomposição destas raízes. Por outro lado, o tratamento ESC-Av apresentou valores de Ds numericamente menores do que os demais tratamentos, embora a diferença não tenha sido estatisticamente significativa. Na média da camada $0-0,20 \mathrm{~m}$, o tratamento ESC-Av reduziu a Ds em apenas 4,8 \% em relação ao tratamento SD-Av nove meses após a escarificação mecânica. Este resultado se assemelha ao de Camara \& Klein (2005a), que observaram redução da Ds de 3,7 \% seis meses após a escarificação.

A porosidade do solo foi um indicador mais sensível às alterações induzidas pelos tratamentos do que a Ds. A Ma foi alterada em todas as camadas avaliadas, e a Mi apenas nas camadas $0-0,05$ e na média da camada $0-0,20 \mathrm{~m}$. A Pt somente teve alterações significativas na camada mais superficial do solo. Observou-se que os tratamentos com consórcio de aveia-preta e nabo-forrageiro foram eficientes em aumentar a $\mathrm{Ma}$ em todas as camadas avaliadas. O escarificador isoladamente somente apresentou aumento de Ma na camada $0-0,05 \mathrm{~m}$. Tais resultados confirmam a limitada persistência do efeito do escarificador como alternativa de descompactação em solo de textura muito argilosa: em um período de apenas nove meses, o solo retornou à sua condição original na camada $0,05-0,20 \mathrm{~m}$. Por sua vez, o consórcio de aveia-preta e nabo-forrageiro permitiram o aumento da Ma tanto quando utilizado como método único para descompactação do solo como quando associado ao escarificador. Nesta situação, as raízes do nabo-forrageiro e da aveia-preta que se 
Quadro 3. Densidade do solo (Ds), macroporosidade (Ma), microporosidade (Mi) e porosidade total (Pt) de um Latossolo Vermelho distroférrico sob diferentes sistemas de manejo

\begin{tabular}{|c|c|c|c|c|}
\hline Tratamento & Ds & Ma & Mi & $\mathrm{Pt}$ \\
\hline & $\mathrm{Mg} \mathrm{m}^{-3}$ & $\longrightarrow$ & $n^{3} m^{-3}$ & - \\
\hline & \multicolumn{4}{|c|}{ Profundidade $0,0-0,05 \mathrm{~m}$} \\
\hline $\mathrm{SD}-\mathrm{Av}$ & 1,07 & $0,08 \mathrm{~b}^{(1)}$ & $0,43 \mathrm{ab}$ & $0,52 \mathrm{~b}$ \\
\hline $\mathrm{SD}-\mathrm{Nb}+\mathrm{Av}$ & 1,12 & $0,12 \mathrm{ab}$ & $0,39 \mathrm{~b}$ & $0,51 \mathrm{~b}$ \\
\hline ESC -Av & 1,00 & $0,13 \mathrm{ab}$ & $0,53 \mathrm{a}$ & $0,66 \mathrm{a}$ \\
\hline $\mathrm{ESC}-\mathrm{Nb}+\mathrm{Av}$ & 1,06 & $0,14 \mathrm{a}$ & $0,47 \mathrm{ab}$ & $0,61 \mathrm{ab}$ \\
\hline Inicial & 1,09 & 0,07 & 0,45 & 0,52 \\
\hline Teste F & $1,90 \mathrm{~ns}$ & $4,53^{*}$ & $4,82^{*}$ & $6,71^{*}$ \\
\hline CV (\%) & 6,43 & 19,76 & 11,54 & 9,73 \\
\hline \multicolumn{5}{|c|}{ Profundidade $0,05-0,10 \mathrm{~m}$} \\
\hline $\mathrm{SD}-\mathrm{Av}$ & 1,31 & $0,03 \mathrm{~b}$ & 0,37 & 0,40 \\
\hline $\mathrm{SD}-\mathrm{Nb}+\mathrm{Av}$ & 1,26 & $0,10 \mathrm{a}$ & 0,31 & 0,41 \\
\hline ESC -Av & 1,20 & $0,04 \mathrm{~b}$ & 0,42 & 0,46 \\
\hline $\mathrm{ESC}-\mathrm{Nb}+\mathrm{Av}$ & 1,23 & $0,08 \mathrm{a}$ & 0,38 & 0,46 \\
\hline Inicial & 1,36 & 0,02 & 0,36 & 0,38 \\
\hline Teste F & $0,30 \mathrm{~ns}$ & 25,89 * & $1,57 \mathrm{~ns}$ & $0,94 \mathrm{~ns}$ \\
\hline CV (\%) & 13,49 & 28,49 & 19,66 & 17,32 \\
\hline \multicolumn{5}{|c|}{ Profundidade $0,10-0,15 \mathrm{~m}$} \\
\hline $\mathrm{SD}-\mathrm{Av}$ & 1,36 & $0,03 \mathrm{~b}$ & 0,39 & 0,42 \\
\hline $\mathrm{SD}-\mathrm{Nb}+\mathrm{Av}$ & 1,37 & $0,06 \mathrm{a}$ & 0,32 & 0,37 \\
\hline ESC -Av & 1,31 & $0,02 \mathrm{~b}$ & 0,42 & 0,44 \\
\hline $\mathrm{ESC}-\mathrm{Nb}+\mathrm{Av}$ & 1,34 & $0,06 \mathrm{a}$ & 0,35 & 0,41 \\
\hline Inicial & 1,33 & 0,03 & 0,37 & 0,40 \\
\hline Teste F & 0,49 ns & 12,80 * & $2,38 \mathrm{~ns}$ & $0,87 \mathrm{~ns}$ \\
\hline CV (\%) & 5,13 & 26,64 & 16,15 & 15,03 \\
\hline \multicolumn{5}{|c|}{ Profundidade $0,15-0,20 \mathrm{~m}$} \\
\hline SD - Av & 1,31 & $0,02 \mathrm{c}$ & $0,38 \mathrm{a}$ & 0,40 \\
\hline $\mathrm{SD}-\mathrm{Nb}+\mathrm{Av}$ & 1,36 & 0,06 a & $0,31 \mathrm{~b}$ & 0,37 \\
\hline ESC -Av & 1,28 & $0,03 \mathrm{bc}$ & $0,38 \mathrm{a}$ & 0,41 \\
\hline $\mathrm{ESC}-\mathrm{Nb}+\mathrm{Av}$ & 1,40 & $0,04 \mathrm{ab}$ & $0,34 \mathrm{ab}$ & 0,39 \\
\hline Inicial & 1,32 & 0,02 & 0,39 & 0,41 \\
\hline Teste F & $0,97 \mathrm{~ns}$ & $19,68^{*}$ & $4,93^{*}$ & $0,99 \mathrm{~ns}$ \\
\hline CV (\%) & 7,95 & 20,75 & 8,58 & 8,91 \\
\hline \multicolumn{5}{|c|}{ Profundidade $0,0-0,20 \mathrm{~m}$} \\
\hline SD - Av & 1,26 & $0,04 \mathrm{~b}$ & $0,39 \mathrm{ab}$ & 0,43 \\
\hline $\mathrm{SD}-\mathrm{Nb}+\mathrm{Av}$ & 1,28 & 0,08 a & $0,34 \mathrm{~b}$ & 0,42 \\
\hline $\mathrm{ESC}-\mathrm{Av}$ & 1,20 & $0,05 \mathrm{~b}$ & $0,44 \mathrm{a}$ & 0,49 \\
\hline $\mathrm{ESC}-\mathrm{Nb}+\mathrm{Av}$ & 1,26 & $0,08 \mathrm{a}$ & $0,39 \mathrm{ab}$ & 0,47 \\
\hline Inicial & 1,27 & 0,04 & 0,39 & 0,43 \\
\hline Teste F & $0,87 \mathrm{~ns}$ & $22,76^{*}$ & 3,94 * & $2,29 \mathrm{~ns}$ \\
\hline CV (\%) & 5,78 & 15,16 & 11,19 & 9,94 \\
\hline
\end{tabular}

(1) Médias seguidas por letras distintas, na mesma coluna e profundidade, diferem-se pelo teste Tukey $(p<0,05) .{ }^{\text {ns: }}$ t teste $\mathrm{F}$ não significativo. *: teste F significativo $(\mathrm{p}<0,05)$. SD-Av: aveia-preta em semeadura direta. SD-Nb+Av: consórcio de nabo-forrageiro e aveia-preta em semeadura direta. ESC-Av: aveia-preta em solo escarificado. ESC-Nb+Av: consórcio de nabo-forrageiro e aveia-preta em solo escarificado.

desenvolveram no solo escarificado provavelmente evitaram a reconsolidação do solo e que este retornasse ao seu estado de compactação original, conforme verificado no tratamento ESC-Av. Na média da camada 0-0,20 m, o consórcio de aveia-preta e naboforrageiro (escarificação biológica), associado ou não ao uso do escarificador mecânico, duplicou os valores de Ma do solo em relação ao tratamento $\mathrm{SD}-\mathrm{Av}$ e à condição original do solo, enquanto o uso do escarificador mecânico como método isolado de descompactação não promoveu aumento deste atributo. Neste caso, infere-se que o efeito da escarificação biológica foi preponderante sobre a escarificação mecânica. 
O tratamento ESC-Av apresentou os maiores valores de Mi nas camadas de solo $0-0,05$ e $0-0,20 \mathrm{~m}$ e de Pt na camada 0-0,05 m. Esses resultados podem indicar que, devido ao processo de reconsolidação do solo, o espaço aéreo formado pela operação de escarificação teve baixa estabilidade e foi reduzido no transcorrer dos nove meses entre a escarificação e as avaliações realizadas. Camara \& Klein (2005a) também não observaram diferenças significativas entre os valores de Ma, Mi e Pt de um Latossolo após seis meses de intervalo entre a escarificação e as avaliações. Já Secco \& Reinert (1997) observaram persistência do aumento da porosidade total do solo até 10 meses após a escarificação. Segundo Busscher et al. (2002), a persistência do efeito do escarificador é dependente do volume e da intensidade da precipitação, sendo assim, em anos mais chuvosos, como foi registrado durante a condução deste experimento, o solo tende a se reconsolidar mais rapidamente. Com base nisto, infere-se que a escarificação mecânica, em solos de textura muito argilosa, deveria ser realizada imediatamente antes da cultura de maior interesse econômico ou alternativamente associada à cultura de cobertura com raiz pivotante durante a entressafra.

O uso do consórcio de aveia-preta e nabo-forrageiro, isoladamente ou associado ao escarificador, promoveu a redução dos valores de RP do solo em relação ao tratamento SD-Av (Figura 2a). O tratamento EscAv teve comportamento intermediário, não diferindo significativamente dos demais. Parte destes resultados se deve à maior quantidade de fitomassa aportada e à maior umidade gravimétrica do solo observada nos tratamentos que receberam o consórcio de aveia-preta e nabo-forrageiro no inverno do que aqueles que tiveram apenas a aveia-preta como cultura de cobertura, embora a diferença estatística não tenha sido significativa (Figura 2b). Assim, como reportado anteriormente por Lanzanova et al. (2007), as avaliações de RP, neste trabalho, foram mais sensíveis às alterações nas propriedades físicas do solo do que os valores de Ds.

A partir do $0,07 \mathrm{~m}$ de profundidade no tratamento $\mathrm{SD}-\mathrm{Av}$, os valores de $\mathrm{RP}$ verificados são superiores ao limite de 2,0 MPa, considerado por Taylor et al. (1966) como restritivo ao desenvolvimento de raízes. Por outro lado, Silva et al. (2000) observaram, em um Latossolo de textura argilosa, redução do rendimento de grãos de soja quando a RP foi superior a 1,8 $\mathrm{MPa}$. Neste caso, o tratamento SD-Av já apresentou valores de RP superiores a 1,8 MPa a partir dos $0,05 \mathrm{~m}$ de profundidade, e o tratamento ESC-Av somente os teve a partir do 0,11 m e os tratamentos SD-Nb+Av e ESC$\mathrm{Nb}+\mathrm{Av}$ não apresentaram valores superiores a $1,6 \mathrm{MPa}$ na camada $0-0,20 \mathrm{~m}$.

A RP relacionou-se significativamente com a $\mathrm{Ma}$ $\left(\mathrm{R}^{2}=0,89, \mathrm{p}<0,01\right)$, tomando-se a média da $\mathrm{RP}$ e Ma nas camadas de $0-0,05 ; 0,05-0,10 ; 0,10-0,15$; e 0,15-0,20 m (Figura 3). Verifica-se que a cada $0,01 \mathrm{~m}^{3} \mathrm{~m}^{-3}$ de aumento da Ma ocorre uma redução

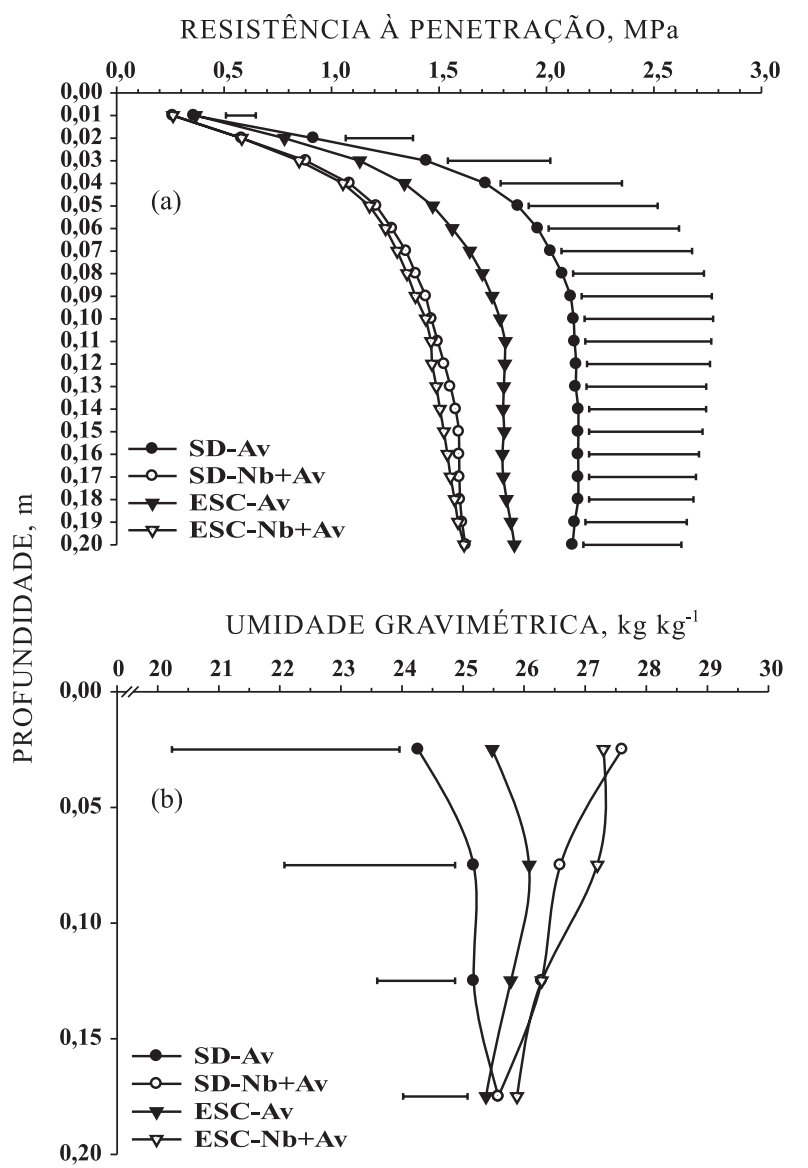

Figura 2. Resistência à penetração (a) e umidade gravimétrica (b) de um Latossolo Vermelho distroférrico sob diferentes sistemas de manejo. As barras horizontais indicam a diferença mínima significativa pelo teste de Tukey $(p<0,05)$. SD-Av: aveia-preta em semeadura direta; SD-Nb+Av: consórcio de nabo-forrageiro e aveia-preta em semeadura direta; ESC-Av: aveia-preta em solo escarificado; ESC-Nb+Av: consórcio de nabo-forrageiro e aveia-preta em solo escarificado.

de 0,1 MPa nos valores de RP. Cunha et al. (2002) demonstraram a alta correlação entre $\mathrm{RP}$ e os valores de Ds e a umidade do solo. Tormena et al. (2002) atribuíram a variação nos valores de $\mathrm{RP}$ em solos com condições de umidade semelhantes aos valores de Ds e Ma.

A escarificação mecânica como método isolado de descompactação não favoreceu a infiltração de água no solo (Figura 4). No entanto, o uso do consórcio de nabo-forrageiro e aveia-preta em semeadura direta, ou após a escarificação mecânica do solo, aumentou significativamente a lâmina de água infiltrada no solo. Nos tratamentos SD-Nb+Av e ESC-Nb+Av, após duas horas de avaliações, a lâmina de água infiltrada foi de 224 e $235 \mathrm{~mm}$, respectivamente, enquanto nos tratamentos SD-Av e ESC-Av foi de 149 e 164 mm, 


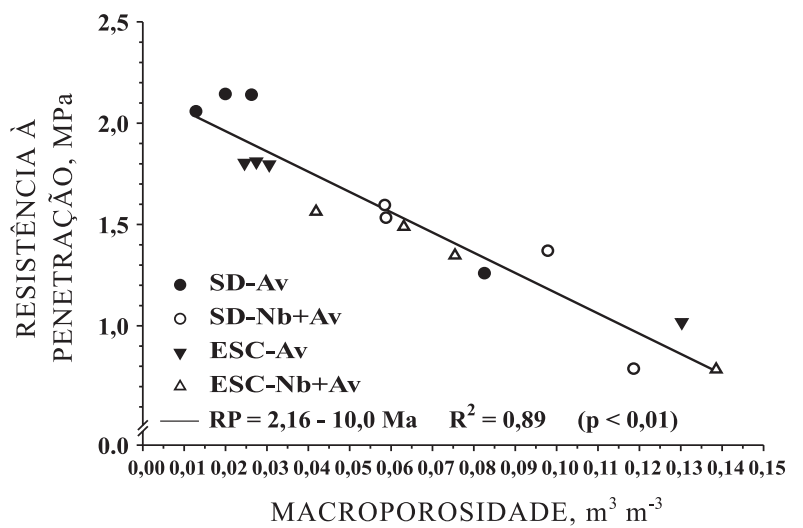

Figura 3. Relação entre macroporosidade e resistência à penetração do solo na média das camadas $0-0,05 ; 0,05-0,10 ; 0,10-0,15 ; \mathrm{e} 0,15-0,20 \mathrm{~m}$ de profundidade de um Latossolo Vermelho distroférrico sob diferentes sistemas de manejo. SD-Av: aveia-preta em semeadura direta; SD$\mathrm{Nb}+\mathrm{Av}$ : consórcio de nabo-forrageiro e aveiapreta em semeadura direta; ESC-Av: aveia-preta em solo escarificado; ESC-Nb+Av: consórcio de nabo-forrageiro e aveia-preta em solo escarificado.

respectivamente $(\mathrm{CV}=57,4 \%)$. O tratamento ESCAv aumentou a lâmina de água infiltrada em apenas $10 \%$ em relação ao tratamento SD-Av transcorridos nove meses da sua operação. Por outro lado, Camara \& Klein (2005b) observaram que, após seis meses de escarificação, em um Latossolo de textura muito argilosa, a taxa básica de infiltração de água no solo se mantinha 3,8 vezes superior àquela observada em solo sob SD, tendo como planta de cobertura de inverno a aveia-preta. Secco \& Reinert (1997) observaram que o efeito da escarificação mecânica não persistiu além de dez meses, o que pode explicar a diferença entre os resultados de infiltração obtidos neste trabalho, com os de Camara \& Klein (2005a).

Os tratamentos com escarificação biológica aumentaram em média 46,6 \% a lâmina de água infiltrada em relação aos demais tratamentos. Resultados distintos foram obtidos por Sobrinho et al. (2003), que observaram redução da taxa de infiltração de água em um Latossolo de textura muito argilosa com o uso do nabo-forrageiro em relação à taxa de infiltração de água após o uso da aveia-preta. No entanto, naquele trabalho, os autores realizaram as avaliações para determinação da infiltração de água no solo logo após o manejo das plantas de cobertura de inverno. Já neste trabalho, a decomposição das raízes, ocorrida nos quatro meses após o manejo das culturas de cobertura, no mês de outubro de 2006 e as avaliações de infiltração de água no mês de fevereiro de 2007, podem explicar o aumento da infiltração de água nos tratamentos SD-Nb+Av e ESC-Nb+Av. Os bioporos formados pelas raízes do nabo têm alta estabilidade e, após a sua decomposição, atuam como canais preferenciais para a infiltração da água no solo e para o crescimento radicular como proposto por Willians \& Weil (2004). Sasal \& Andriulo (2005), à semelhança do verificado neste trabalho, observaram que o naboforrageiro aumentou as taxas de infiltração de água no solo em um Argissolo da Argentina.

A avaliação da infiltração de água no solo em pleno florescimento da cultura da soja e não no período entre o manejo das plantas de cobertura de solo de inverno e a semeadura da soja, como realizado por Camara \& Klein (2005a) e Sobrinho et al. (2003), parece ser mais adequado devido à importância da dinâmica da água no solo sobre o rendimento da soja neste período crítico de desenvolvimento da cultura (Bertalo, 1987).

As lâminas de água infiltrada no final de duas horas de avaliação tiveram relação significativa com a macroporosidade do solo na camada $0-0,20 \mathrm{~m}\left(\mathrm{R}^{2}=\right.$ $0,82, \mathrm{P}<0,01)$ e com a $\mathrm{RP}$ média $\left(\mathrm{R}^{2}=0,54, \mathrm{p}<0,05\right)$ (Figura 5). Esses dados concordam com os de Sasal \& Andriulo (2005), que observaram alta relação $\left(R^{2}=0,70, p<0,01\right)$ entre a taxa básica de infiltração de água em um Argissolo da Argentina e a proporção de macroporos na camada superficial desse solo.

$\mathrm{O}$ aumento da macroporosidade do solo (Sasal \& Andriulo, 2005), a maior estabilidade (Willians \& Wiel, 2004), a continuidade e verticalidade (Sasal et al., 2006) dos bioporos formados pelo sistema radicular do nabo-forrageiro são determinantes para justificar o aumento da infiltração de água no solo verificado neste trabalho. A maior sensibilidade do indicador RP em

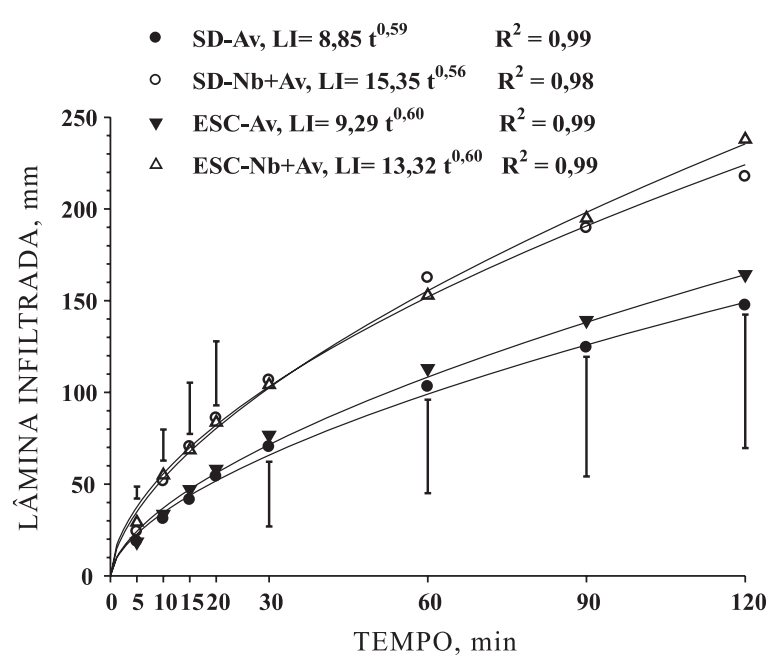

Figura 4. Lâmina de água infiltrada em um Latossolo Vermelho distroférrico sob diferentes sistemas de manejo. As barras verticais correspondem à diferença mínima significativa pelo teste de Tukey $(p<0,05)$. SD-Av: aveia-preta em semeadura direta; $\mathrm{SD}-\mathrm{Nb}+\mathrm{Av}$ : consórcio de naboforrageiro e aveia-preta em semeadura direta; ESC-Av: aveia-preta em solo escarificado; ESC$\mathrm{Nb}+\mathrm{Av}$ : consórcio de nabo-forrageiro e aveiapreta em solo escarificado. 
(a)

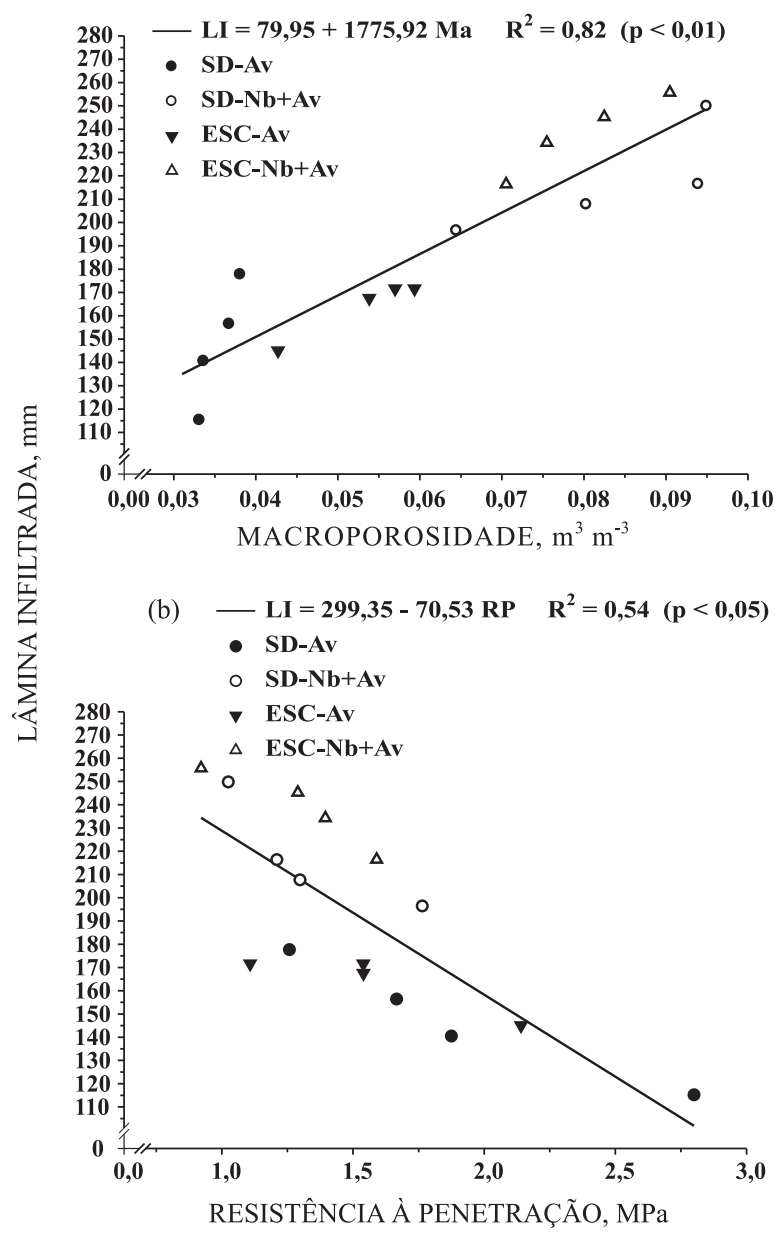

Figura 5. Relação entre macroporosidade na camada 0-0,20 m do solo e lâmina total de água infiltrada no solo (a) e resistência à penetração na camada 0-0,20 $\mathrm{m}$ do solo e lâmina total de água infiltrada no solo (b) de um Latossolo Vermelho distroférrico sob diferentes sistemas de manejo. SD-Av: aveia-preta em semeadura direta; SD$\mathrm{Nb}+\mathrm{Av}$ : consórcio de nabo-forrageiro e aveiapreta em semeadura direta; ESC-Av: aveia-preta em solo escarificado; ESC-Nb+Av: consórcio de nabo-forrageiro e aveia-preta em solo escarificado.

relação à Ds e a sua relação com a infiltração de água no solo demonstraram que a RP foi um indicador eficiente das condições físicas do solo.

\section{Rendimento de soja}

Os elevados índices pluviométricos observados durante o período de condução do experimento, especialmente no verão de 2006/2007 (Figura 6), provavelmente amenizaram os reflexos da compactação do solo sobre o rendimento da soja (Quadro 4). Neste período, a precipitação acumulada durante o ciclo da soja foi $47,8 \%$ superior aos valores históricos observados na região, na média dos anos 1931-1974. Com isto, em todos os tratamentos os rendimentos alcançados foram elevados, com média geral de 3,53 $\mathrm{Mg} \mathrm{ha}^{-1}, 91,8 \%$ acima da produtividade média da soja no Estado do RS entre os anos 1998-2007, e 36,3 \% acima da produtividade média da soja no RS, na safra 2006/2007 (IBGE, 2007).

O maior rendimento de soja foi obtido no tratamento ESC-Nb+Av (3,73 $\left.\mathrm{Mg} \mathrm{ha}^{-1}\right)$, que não diferiu estatisticamente de $\mathrm{SD}-\mathrm{Nb}+\mathrm{Av}$, com produtividade $7,5 \%$ superior à média dos demais tratamentos. $\mathrm{O}$ maior rendimento de soja observado nos tratamentos $\mathrm{ESC}-\mathrm{Nb}+\mathrm{Av}$ e $\mathrm{SD}-\mathrm{Nb}+\mathrm{Av}$ pode ser atribuído à interação entre a maior cobertura de solo proporcionada pela elevada produção de fitomassa (Quadro 2), melhores condições físicas (Quadro $3 \mathrm{e}$ Figura 2) e maior infiltração de água no solo (Figura 4). Ainda, os maiores valores de macroporosidade do solo (Quadro 3) observados nos tratamentos ESC-Nb+Av e SD-Nb+Av podem ter

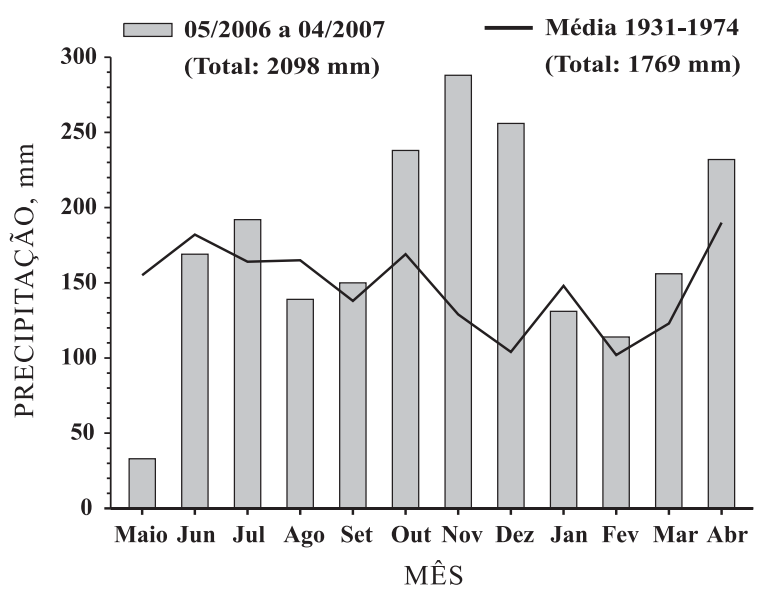

Figura 6. Índices pluviométricos históricos (IPAGRO, 1989) e observados durante a realização do experimento em Santa Rosa, RS.

Quadro 4. Rendimento de grãos de soja em um Latossolo Vermelho distroférrico sob diferentes sistemas de manejo

\begin{tabular}{lc}
\hline Tratamento & Rendimento de grãos \\
\hline & $\mathrm{Mg} \mathrm{ha}^{-1}$ \\
$\mathrm{SD}-\mathrm{Av}$ & $3,45 \mathrm{~b}^{*}$ \\
$\mathrm{SD}-\mathrm{Nb}+\mathrm{Av}$ & $3,49 \mathrm{ab}$ \\
$\mathrm{ESC}-\mathrm{Av}$ & $3,47 \mathrm{~b}$ \\
$\mathrm{ESC}-\mathrm{Nb}+\mathrm{Av}$ & $3,73 \mathrm{a}$
\end{tabular}

SD-Av: aveia-preta em semeadura direta; SD-Nb+Av: consórcio de nabo-forrageiro e aveia-preta em semeadura direta; ESC-Av: aveia-preta em solo escarificado; ESC-Nb+Av: consórcio de nabo-forrageiro e aveia-preta em solo escarificado. "Médias seguidas pelas mesmas letras não diferem entre si pelo teste de Tukey $(p<0,05)$. 
implicado uma drenagem mais rápida e melhor oxigenação do solo, o que pode ter contribuído para o maior rendimento de soja neste ano de elevadas precipitações durante o ciclo da cultura (Figura 6).

\section{CONCLUSÕES}

1. O consórcio de nabo-forrageiro com aveia-preta aumentou a produção de fitomassa aportada ao solo quando comparado ao cultivo da aveia-preta solteira.

2. A escarificação biológica foi eficiente em aumentar a macroporosidade do solo, diminuir a resistência do solo à penetração e melhorar a infiltração de água em um Latossolo inicialmente compactado.

3. O efeito da escarificação mecânica no Latossolo de textura muito argilosa, em época de elevada precipitação, foi temporário, não constando melhoria nas condições físicas nove meses após a operação.

4. A escarificação biológica aumentou a persistência da melhoria das condições físicas do solo induzidas pela escarificação mecânica.

5. Os maiores rendimentos de grãos de soja foram observados após a escarificação biológica do solo isolada ou associada ao uso do escarificador.

\section{AGRADECIMENTOS}

Aos Srs. A. Gassen, E. Jantsch, H. Fabrício e M. Racho, produtores rurais do município de Santa Rosa - RS, pela cessão das áreas destinadas ao experimento e pelo apoio na sua execução. À Cooperativa Mista São Luiz - COOPERMIL de Santa Rosa - RS, pelo apoio técnico e financiamento parcial desta pesquisa. Ao CNPq e à CAPES, pela concessão das bolsas dos envolvidos neste trabalho.

\section{LITERATURA CITADA}

ABREU, S.L.; REICHERT, J.M. \& REINERT, D.J. Escarificação mecânica e biológica para a redução da compactação em Argissolo franco-arenoso sob plantio direto. R. Bras. Ci. Solo, 28:519-531, 2004.

BAVER, L.D.; GARDNER, W.H. \& GARDNER, W.R. Soil physics. 4.ed. New York, John Wiley \& Sons, 1972. 498p.

BENJAMIN, J.G. Tillage effects on near-surface soil hydraulic properties. Soil Till. Res., 26:277-288, 1993.

BERLATO, M.A. Modelo de relação entre o rendimento de grãos de soja e o déficit hídrico para o Estado do Rio Grande do Sul. São José dos Campos, Instituto Nacional de Pesquisas Espaciais 1987. 93p. (Tese de Doutorado)
BeUtler, A.N.; CENTURION, J.F.; ROQUE, C.G. \& FERRAZ, M.V. Densidade relativa ótima de Latossolos Vermelhos para a produtividade de soja. R. Bras. Ci. Solo, 29:843-849, 2005 .

BUSSCHER, W.J.; BAUER, P.J. \& FREDERICK, J.R. Recompaction of a coastal loamy sand after deep tillage as a function of subsequent cumulative rainfall. Soil Till. Res., 68:49-57, 2002.

CALEGARI, A. Plantas para adubação verde de inverno no sudoeste do Paraná. Londrina, Fundação Instituto Agronômica do Paraná, 1990. 37p. (Boletim Técnico, 35).

CAMARA, R.K. \& KLEIN, V.A. Escarificação em plantio direto como técnica de conservação do solo e da água. R. Bras. Ci. Solo, 29:789-796, 2005a.

CAMARA, R.K. \& KLEIN, V.A. Propriedades físico-hídricas do solo sob plantio direto escarificado e rendimento da soja. Ci. Rural, 35:813-819, 2005b.

CANILLAS, E.C. \& SALOKHE, V.M. Regression analysis of some factors influencing soil compaction. Soil Till. Res., 61:167-178, 2001.

CINTRA, F.LD. \& MIELNICZUK, J. Potencial de algumas espécies vegetais para a recuperação de solos com propriedades físicas degradadas. R. Bras. Ci. Solo, 7:197201,1983

CHANG, C. \& LINDWALL, C.W. Effects of tillage and crop rotation on physical properties of a loam soil. Soil Till. Res., 22:383-389, 1992.

CUBILLA, M.; REINERT, D.J.; AITA, C. \& REICHERT, J.M. Plantas de cobertura do solo: uma alternativa para aliviar a compactação em sistema plantio direto. R. Plantio Direto, 71:29-32, 2002.

CUNHA, J.P.A.R.; VIEIRA, L.B. \& MAGALHÃES, A.C. Resistência mecânica do solo à penetração sob diferentes densidades e teores de água. Eng. Agric., 10:1-4, 2002.

EMPRESA BRASILEIRA DE PESQUISA AGROPECUÁRIA EMBRAPA. Centro Nacional de Pesquisa de Solos. Manual de métodos de análise de solo. 2.ed. Brasília, 1997. $212 \mathrm{p}$.

EMPRESA BRASILEIRA DE PESQUISA AGROPECUÁRIA EMBRAPA. Centro Nacional de Pesquisa de Solos. Sistema brasileiro de classificação de solos. 2.ed. Rio de Janeiro, 2006. 306p.

GEE, G.W. \& BAUDER, J.W. Particle-size analysis. In: KLUTE, A., ed. Methods of soil analysis. 2.ed. Madison, American Society of Agronomy, 1986. v.1. p.383-411.

GIACOMINI, S.J.; AITA, C.; VENDRUSCOLO, E.R.O.; CUBILLA, M.; NICOLOSO, R.S. \& FRIES, M.R. Matéria seca, relação $\mathrm{C} / \mathrm{N}$ e acúmulo de nitrogênio, fósforo e potássio em misturas de plantas de cobertura de solo. R. Bras. Ci. Solo, 27:325-334, 2003.

HILLEL, D. Environmental soil physics. New York, Academic Press, 1998. 770p.

HORN, R.; WAY, T. \& ROSTEK, J. Effect of repeated tractor wheeling on stress/strain properties and consequences on physical properties in structured arable soils. Soil Till. Res., 73:101-106, 2003. 
INSTITUTO BRASILEIRO DE GEOGRAFIA E ESTATÍSTICA - IBGE. Levantamento sistemático da produção agrícola. Brasília, 2007. Disponível em: <http://www.ibge.gov.br>. Acesso em 01 de agos. de 2007.

INSTITUTO DE PESQUISAS AGRONÔMICAS - IPAGRO. Observações meteorológicas no Estado do Rio Grande do Sul. Porto Alegre, 1989.

KUBOTA, A.; HOSHIBA, K. \& BORDON, J. Green-manure turnip for soybean based no-tillage farming systems in eastern Paraguay. Sci. Agric., 62:150-158, 2005.

LAL, R. \& VANDOREN, D. Influence of 25 years of continuous corn production by three tillage methods on water infiltration of two soils in Ohio. Soil Till. Res., 16:71-74, 1990.

LANZANOVA, M.E.; NICOLOSO, R.S.; LOVATO, T.; ELTZ, F.L.F.; AMADO, T.J.C. \& REINERT, D.J. Atributos físicos do solo em sistemas de integração lavoura-pecuária sob plantio direto. R. Bras. Ci. Solo, 31:1131-1140, 2007.

LOVATO, T.; MIELNICZUK, J.; BAYER, C. \& VEZZANI, F. Adição de carbono e nitrogênio e sua relação com os estoques no solo e o rendimento do milho em sistemas de manejo. R. Bras. Ci. Solo, 28:175-187, 2004.

MALUF, J.R.T. Nova classificação climática do Estado do Rio Grande do Sul. R. Bras. Agrometeorol., 8:141-150, 2000.

MATERECHERA, S.A.; DEXTER, A.R. \& ALSTON, A.M. Penetration of very strong soils by seedling roots of different plant species. Plant Soil, 135:31-41, 1991.

MICHELON, C.J. Qualidade física de solos irrigados do Rio Grande do Sul e do Brasil Central. Santa Maria, Universidade Federal de Santa Maria, 2005. 92p. (Tese de Mestrado)

MÜLLER, M.M.L.; CECCON, G. \& ROSOLEM, C.A. Influência da compactação do solo em subsuperfície sobre o crescimento aéreo e radicular de plantas de adubação verde de inverno. R. Bras. Ci. Solo, 25:531-538, 2001.

PIERCE, F.J.; FORTIN, M.C. \& STATON, M.J. Periodic plowing effects on soil properties in a no-till farming system. Soil Sci. Soc. Am. J., 58:1782-1787, 1994.

REICHERT, J.M.; REINERT, D.J.; BRAIDA, J.A. Qualidade dos solos e sustentabilidade de sistemas agrícolas. Ci. Amb., 27:29-48, 2003.

REUNIÃO DE PESQUISA DE SOJA DA REGIÃO SUL, 34 Indicações técnicas para a cultura da soja no Rio Grande do Sul e em Santa Catarina 2006/2007. Pelotas, Embrapa Clima Temperado, 2006. 237p

ROSOLEM, C.A.; VALE, L.S.R.; GRASSI FILHO, H. \& MORAES, M.H. Sistema radicular e nutrição do milho em função da calagem e da compactação do solo. R. Bras. Ci. Solo, 18:491-497, 1994.

SASAL, M.C. \& ANDRIULO, A.E. Cambios en la porosidad edáfica bajo siembra directa por la introducción de Raphanus sativus L. (nabo forrajero). R. Invest. Agropec., 34:131-150, 2005.
SASAL, M.C.; ANDRIULO, A.E. \& TABOADA, M.A. Soil porosity characteristics and water movement under zero tillage in silty soils in Argentinian Pampas. Soil Till. Res., 87:9-18, 2006.

SECCO, D. \& REINERT, D.J. Efeitos imediato e residual de escarificadores em Latossolo Vermelho-escuro sob PD. Eng. Agríc., 16:52-61, 1997.

SIDIRAS, N.; HENKLAIN, J.C. \& DERPSCH, R. Comparison of three different tillage systems with respect to some physical properties, the soil and water conservation and the yields of soybean and wheat on an Oxisol. Zeitschrift Acker-und Pflanzenbau, 151:137-148, 1982.

SILVA, V.R.; REINERT, D.J. \& REICHERT, J.M. Resistência mecânica do solo à penetração influenciada pelo tráfego de uma colhedora em dois sistemas de manejo do solo. Ci. Rural, 30:795-801, 2000.

SILVA, V.R.; REINERT, D.J. \& REICHERT, J.M. Fatores controladores da compressibilidade de um Argissolo Vermelho-Amarelo distrófico arênico e de um Latossolo Vermelho distrófico típico. II - Grau de saturação em água. R. Bras. Ci. Solo, 26:9-15, 2002.

SILVA, A.A.; SILVA, P.R.F.; SUHRE, E.; ARGENTA, G.; STRIEDER, M.L. \& RAMBO, L. Sistemas de coberturas de solo no inverno e seus efeitos sobre o rendimento de grãos do milho em sucessão. Ci. Rural, 37:928-935, 2007.

SOBRINHO, T.A.; VITORINO, A.T.C.; SOUZA, L.C.F.; GONÇALVES, M.C. \& CARVALHO, D.F. Infiltração de água no solo em sistemas de plantio direto e convencional. R. Bras. Eng. Agric. Amb., 7:191-196, 2003.

SUZUKI, L.E.A.S.; REINERT, D.J.; REICHERT, J.M. \& LIMA, C.L.R. Densidade restritiva ao sistema radicular em função da argila. In: REUNIÃO BRASILEIRA DE MANEJO E CONSERVAÇÃO DO SOLO E DA ÁGUA, 16., Aracajú, 2006. Anais. Recife, 2006. CD-ROM.

TAYLOR, H.M.; ROBERTSON, G.M. \& PARKER, J.J. Soil strength root penetration relations for medium to coarse textured soil materials. Soil Sci., 102:18-22, 1966.

TEDESCO, M.J.; GIANELLO, C.; BISSANI, C.A.; VOLKWEISS, S.J. \& BOHNEN, H. Análises de solo, plantas e outros materiais. 2.ed. Porto Alegre, Universidade Federal de Rio Grande do Sul, 1995. 174p. (Boletim Técnico, 5)

TORMENA, C.A.; BARBoSA, M.C.; COSTA, A.C.S. \& GONÇALVES, A.C.A. Densidade, porosidade e resistência à penetração em Latossolo cultivado sob diferentes sistemas de preparo do solo. Sci. Agric., 59:795-801, 2002.

VAZQUEZ, L.; MYHRE, D.L.; GALLAHER, R.N.; HANLON, E.A. \& PORTIER, K.M. Soil compaction associated with tillage treatments for soybean. Soil Till Res., 13:35-45, 1989 .

WILLIANS, S.M. \& WEIL, R.R. Crop cover root channels may alleviate soil compaction effects on soybean crop. Soil Sci. Soc. Am. J., 68:1403-1409, 2004. 